\title{
ESSAY AS A FORM OF FINAL CONTROL (EXAM) FOR MASTER'S DEGREE STUDENTS
}

\author{
Svetlana Nesyna \\ Immanuil Kant Baltic Federal University
}

\begin{abstract}
The important goal of Russian universities is development of Master's Degree Programs. It requires profound changes in educational content and methods. This work presents the experience in approbation of essay as a form of exam in education of 20 students of Master Program „Preschool education”. In our study we suppose that using the essay helps to reduce negative effects of traditional forms of control and activates self-development of participants. The incomplete sentences technique as a data-gathering tool was applied after the exam. According to the results, creation of essay contributes to generalization and understanding, comprehension of the problem information, makes cognitive and metacognitive processes more active. Such form of final control gives psychological comfort, creates a situation of success. It strengthens needs for autonomy, competence, relatedness, which are sources of internal motivation as the basis of subjectness and self-development tendency.
\end{abstract}

Keywords: essay, exam, internal motivation, subjectness, self-development.

\section{Введение Introduction}

Значение образования в жизни отдельного человека и общества в целом трудно переоценить, особенно в эпоху глобальных информационных трансформаций. Темпы накопления знаний человечеством ускоряются, требования к профессиональной деятельности усложняются, роль непрерывного образования возрастает. Приоритетной задачей высших учебных заведений России является развитие магистратуры (Константинова, 2013). Выпускнику магистерской программы необходимо не только овладеть необходимым объемом знаний и умений, технологиями и стратегиями познавательной и практической деятельности, отвечающей современным требованиям, но и активизировать «потенциал самообразования» (Попков \& Коржуев, 2010). Перед высшей школой стоят задачи изменения содержания образования и методов работы. В статье представлен опыт апробации эссе как формы итогового контроля в работе с магистрантами. Мы предположили, что использование эссе позволит уменьшить негативные последствия традиционных форм контроля и активизировать саморазвития магистрантов. В исследовании применялась техника незаконченных предложений. 


\section{Теоретическая основа исследования Theoretical basis of research}

В переводе с французского языка эссе означает «опыт», «попытка», «проба». Основоположником жанра «эссе» считается Монтень. «Эссе», в понимании Монтеня, представляет собой литературные пробы («наброски», «эскизы», «очерки»), тем самым автор подчеркивает неокончательность, некатегоричность, субъективный характер работы. «Les Essais» Монтеня появляется на исходе Средневековья, при зарождении новой эпохи и отражает «чувство абсолютной внутренней свободы, каковое и есть истинный нерв того жанра, который с легкой руки Монтеня был назван «эссе»» (Люблинский, 2007, с. 165). Через некоторое время этот термин используется в английском языке Ф. Бэконом; во второй половине 19 века термин появляется в немецком языке благодаря Г. Гримму. В России «эссе» входит в «Большую советскую энциклопедия» в 1934 году (Жолковский, 2008).

В образовании эссе представляет собой форму научноисследовательской работы в виде сочинения-рассуждения относительно небольшого объема со свободной композицией, выражающее индивидуальные впечатления, соображения по конкретному вопросу, проблеме и заведомо не претендующее на полноту и исчерпывающую трактовку предмета. Эссе предполагает выражение автором своей точки зрения, личной субъективной оценки предмета рассуждения, дает возможность нестандартного, оригинального освещения поднимаемой научной проблемы (Шохин \& Кузьминов \& Ясин, 2005; Михайленко, 2012).

Популярность заданий в жанре эссе в высшей школе растет. Проведенный анализ литературы позволил выделить ряд факторов, способствующих росту такой популярности. В современной ситуации подходы к организации учебного процесса в высших учебных заведениях меняются. Во-первых, уменьшается количество аудиторных часов, дающих возможность «живого общения» преподавателя и студента, на смену приходят дистанционные формы работы. Во-вторых, основной упор делается на самостоятельную работу студента как субъекта учебнопрофессиональной деятельности. В-третьих, возникает необходимость в использовании новых форм и технологий, повышающих интерес к предмету и способствующих развитию продуктивного, критического мышления. В-четвертых, приобретает особую важность создание определенного эмоционального фона для осмысления учебного и научного материала (Олещенко, 2010; Михайленко, 2012). Благодаря выделенным особенностям, жанр эссе прочно утвердил свои права не только в гуманитарном знании, но и в обучении студентов. 
С появлением магистратуры в вузах России изменился состав студентов: появилось больше взрослых людей с определенным жизненным и профессиональным опытом. Психологическая природа обучения взрослых представляет собой процесс соединения собственного индивидуального опыта, накапливаемого в практической деятельности, с коллективным опытом других людей, обобщенным в науке и культуре, то есть с социальным опытом. В обучении взрослых большое значение имеют метакогнитивные процессы. Предметное содержание выстраивается проблемно. В обучении взрослых целесообразно использовать совместную и групповую работу, основанную на общении и взаимодействии; постоянный диалог; опору на технологично организованную преподавателем самостоятельную работу; высокий уровень трудности и быстрый темп изучения учебного материала (Михайлова, 2007). Роль преподавателя становится более интерактивной (Горшкова, 2014). Взрослые люди воспринимают обучение как логичное, естественное явление, когда происходят инновации в их профессиональной деятельности и стремятся актуализировать результаты обучения, применить их в ближайшем будущем (Макаровская, 2008).

В работе с магистрантами необходимо учитывать два вида трудностей, с которыми сталкивается взрослый в обучении. В первую группу входят трудности внешнего характера: сложность профессиональной деятельности, обремененность обязательствами в быту, недостаток времени и т.д. Вторую группу составляют трудности внутреннего (психологического) характера: стремление к позитивным изменениям в жизни и страх перед взятой на себя ответственностью; желание перемен и страх перемен в стабильном образе жизни; сомнения в своих способностях к обучению, страх демонстрации неумения работать с современными технологиями. Большое количество взрослых людей находятся под влиянием мифа о возрастных ограничениях способности учиться в зрелых возрастах (Михайлова, 2007). Создание оптимальных психологических условий - важное условие эффективного обучения взрослых.

Развитие взрослого человека представляет собой процесс саморазвития. По данным исследования Е. Паппас и Дж. Паппас, выделяются три группы барьеров на пути саморазвития познавательного потенциала, эффективного мышления и поведения современных студентов: 1) чрезмерная электронная стимуляция; 2) дисфункциональные отношения со временем; 3) трудности в принятии намеренных решений (Щукина, 2014). Важная дидактическая цель высшего образования «запуск мотивационно-потребностного механизма «самости» личности студента» (Андреев В.И., 2013, с. 260), создание условий для творческого саморазвития. В работе с магистрантами большое значение имеет актуализация внутренней мотивации деятельности как основы субъектной 
позиции в обучении и стремления к саморазвитию. Источником внутренней мотивации с позиции теории самодетерминации является удовлетворенность потребностей в автономии, компетентности и в том, чтобы быть связанным с другими людьми. Потребность в автономии означает стремление чувствовать выбор и собственную детерминацию своего поведения. Потребность в компетентности - стремление чувствовать себя успешным, компетентным деятелем, справляющимся с задачами выполняемой деятельности. Под потребностью быть связанным с другими понимается стремление иметь надежную связь, быть понятым и принятым (Гордеева \& Сычев \& Осин, 2013).

В организации работы с магистрантами необходимо учитывать тенденцию последних лет, которую В.Н. Косырев назвал «отчуждением учебного труда студентов». Это такое отношение студента к учению, при котором продукты его деятельности, он сам, а также преподаватели, администрация, другие студенты и социальные группы, как носители норм, установок и ценностей учебной деятельности, выступают для него как нечто чуждое его самости (Косырев, 2009). Если продукты учебнопрофессиональной деятельности студентов используются только для выставления преподавателем оценок, то они, по большому счету, оказываются бесполезными. Необходимо сделать результаты труда магистрантов значимыми для всей группы.

Таким образом, основой для выбора эссе как формы проведения итогового контроля стали: во-первых, психологические особенности обучения взрослых; во-вторых, актуализация внутренней мотивации, источниками которой являются потребность в автономии, компетентности, связанности с другими, в том числе через признание значимости вклада каждого в итоговый результат. В своей работе мы предположили, что использование эссе позволит уменьшить негативные последствия традиционных форм контроля и активизировать саморазвития магистрантов.

\section{Организация исследования Research design}

В Высшей школе педагогики Балтийского федерального университета им. И. Канта реализуется магистерская программа «Дошкольное образование». Магистранты второго года обучения в первом семестре имеют возможность изучать дисциплину по выбору «Социокультурные условия развития современных детей дошкольного возраста». Эта дисциплина входит в вариативную часть магистерской программы и завершается экзаменом. Цель освоения дисциплины - уметь анализировать и учитывать в профессиональной деятельности социокультурные условия развития современных дошкольников. 
Дисциплину «Социокультурные условия развития современных детей дошкольного возраста» изучали 20 человек: в 2013-2014 учебном году - 12 магистрантов, в 2014-2015 учебном году - 8 магистрантов. Опыт первой апробации эссе представлен в другой нашей работе (Несына, 2014).

Изучение учебной дисциплины включало несколько этапов. Первый этап содержал вводный лекционный блок и практические занятия с обсуждением различных социокультурных условий и факторов развития современных дошкольников. Второй этап начинался с «мозгового штурма» по определению наиболее значимых условий развития дошкольника в современном мире. По итогам этой работы магистранты выбирали индивидуальные творческие задания. Результаты индивидуальной работы становились предметом изучения всей группы. В 2013-2014 учебном году совместный «мозговой штурм» не проводился, участники осуществляли индивидуальный выбор проблемных вопросов. На завершающем этапе магистранты получили задание подготовить эссе «Социокультурные условия развития современных дошкольников» на основе материалов лекций, практических занятий, результатов индивидуальных творческих проблемных заданий каждого участника группы и собственного профессионального опыта, так как подавляющее большинство магистрантов - работники системы дошкольного образования. Для всех магистрантов это был новый вид работы. В процессе подготовки к экзамену магистранты имели возможность прислать эссе на предварительную проверку и, получив обратную связь от преподавателя, улучшить результат. Этой возможностью воспользовались $50 \%$ магистрантов в 2013-2014 учебном году и 100\% - в 2014-2015 учебном году. Экзамен проводился в форме защиты эссе, после чего группа обобщала представленные материалы и формулировала заключительные выводы по курсу.

После экзамена магистрантам было предложено завершить незаконченные предложения в письменной форме: отметить положительные и отрицательные стороны эссе как формы итогового контроля по учебной дисциплине. Также участникам был задан вопрос о вкладе изученной дисциплины в их развитие.

\section{Результаты и обсуждение Results and discussion}

Было получено 85 высказываний, из них 88,24\% высказываний о положительных сторонах эссе и $11,76 \%$ - об отрицательных. Обратимся к анализу положительных сторон эссе как формы итогового контроля. В ходе контент-анализа были выделены следующие категории (Тab.1). 
Tab.1. Положительные стороны эссе как формы итогового контроля Positive aspects of essay as a form of exam

\begin{tabular}{|c|c|c|}
\hline № & $\begin{array}{l}\text { Kamezopuи } \\
\text { Categories }\end{array}$ & $\begin{array}{l}\text { Yacmoma }(\%) \\
\text { Frequency }\end{array}$ \\
\hline 1. & $\begin{array}{l}\text { «Возможностьобобщения, осмысленияматериала» } \\
\text { «Generalization, understanding and comprehension of material» }\end{array}$ & 21.33 \\
\hline 2. & $\begin{array}{l}\text { «Развиваюший потенциал» } \\
\text { «Dеvеlopтепt» } \\
\text { «Возможность высказать свою точку зрения» } \\
\text { «Оррогtunity to express the point of view» }\end{array}$ & $\begin{array}{l}17.33 \\
17.33\end{array}$ \\
\hline 3. & $\begin{array}{l}\text { «Структурирование материала» } \\
\text { «Structuringofmaterials» } \\
\text { «Стимулирование самостоятельной работы»» } \\
\text { «Independent work» }\end{array}$ & 9.33 \\
\hline 4. & $\begin{array}{l}\text { «Психологический комфорт» } \\
\text { «Рsychologicalcomfort» } \\
\text { «Творческий характер» } \\
\text { «Сrеativity» } \\
\text { «Влияние на профессиональную деятельность» } \\
\text { «еffects on professional activities» }\end{array}$ & $\begin{array}{l}5.33 \\
5.33 \\
5.33\end{array}$ \\
\hline 5. & $\begin{array}{l}\text { «Общаяположительнаяоценка» } \\
\text { «General positive assessment» }\end{array}$ & 4.00 \\
\hline 6. & 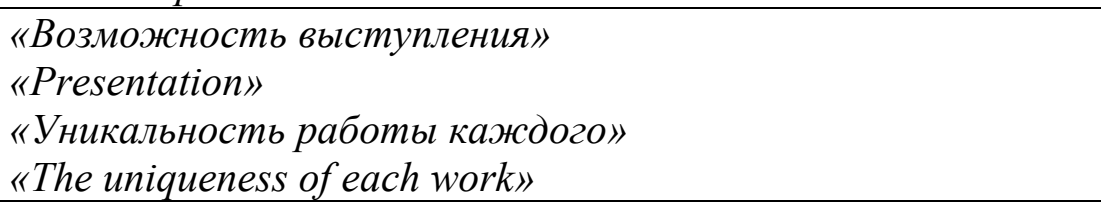 & 2.68 \\
\hline
\end{tabular}

Наибольшее количество высказываний о положительных сторонах относится к категории «Возможность обобщения, осмысления материала»- 21,33\%. К этой категории были отнесены следующие высказывания: «помогает осознать материал», «появляется глубина понимания проблем», «помогает осмыслить информацию», «заставляет задуматься о происходящем вокруг», «выяснение значимого» и т.д. Второе место занимают две категории: «Развивающий потенциал» («учит аргументировать», «можно поспорить с собой», «развивает мылление» $и$ m.д.) и «Возможность высказать свою точку зрения» («можно высказать свои мысли», «высказываешь свой взгляд на происходящее» и т.д.) - по $17,33 \%$. На третьем месте - категории «Структурирование материала» («информация логично выстраивается», «можно собрать мысли в кучу» и m.д.) и «Стимулирование самостоятельной работы» («самостоятельный вклад», «сам анализируешь большое количество информации» и т.д.) - по 9,33\%. Четвертое место занимают категории: «Психологический комфорт» («удобный вид работыл», «на экзамене чувствуешь себя уверенно» и т.д.), «Творческий характер» («творческий поиск», «творческая работа» $и$ m.д.), «Влияние на профессиональную деятельность» («могу применить 
материальи курса в работе», «связь с практикой», «меняется отношение к работе», «появляются новые идеи для работыл и т.д.) - по 5,33\%. Наиболее редкие оказались категории «Общая положительная оценка», «Возможность выступления» и «Уникальность работы каждого» - по $2,68 \%$.

Высказываний об отрицательных сторонах эссе значительно меньше в 7,5 раз. Преобладает категория «Трудоемкость» (40\%): указывается на сложность этой работы, большое количество времени, затраченное на нее. Около трети высказываний относится к «Ограничению объема» $(30 \%)$, в них содержится мысли о том, что сложно в сжатой форме изложить основные идеи. Единичные высказывания о вероятности плагиата, об отсутствии опыта выполнения подобных заданий.

Работа над эссе на завершающем этапе изучения дисциплины способствует лучшему обобщению и осмыслению проблемного содержания курса. Включение элементов проблемности в задание для итогового контроля способствует возникновению интеллектуального напряжения, связанного с наличием препятствия для привычного хода действия и мысли. Для преодоления этого состояния нужно предпринять усилия в поиске новых способов действия, в процессе чего активизируется познавательная деятельность, возникает необходимость самостоятельной работы с информационными источниками. Магистрантам необходимо принять намеренное и аргументированное решение относительно наиболее значимых условий развития современного дошкольника и выразить это решение в тексте работы. Это актуализирует проявление креативности и субъектности.

Ситуация выбора актуализирует потребность в автономии. Ситуация успеха дает возможность магистранту удовлетворить потребность в компетентности. Представление результатов работы группе, подготовка материалов для рассылки другим участникам, осознание того, что индивидуальный результат каждого вносит вклад в итоговое задание, способствует реализации потребности в связанности с другими.

Категория «Влияние на профессиональную деятельность» в материалах незаконченных предложений встречается редко, но влияние выполненной магистрантами работы выражено в ответе на вопрос о вкладе учебной дисциплины «Социокультурные условия развития современных детей дошкольного возраста» в развитие участников. Приведем некоторые ответы: «Я могупо-новому, глубже взглянуть на свою профессиональную деятельность»; "Помогает мне почувствовать себя важным звеном в этой цепочке (сочиокультурной деятельности)»; «Повышается уровень профессионального образования, это помогает в практической деятельности, позволяет посмотреть на свою работу под другим углом»; «Изучение дисчиплины помогло более глубоко понять современного ребенка и учесть его особенности в работе с ним, его родителями, 
педагогами»; "Я теперь по-другому буду работать с семьей»; "Я смогла глубже изучить проблемь наших дней, теперь знаю, на какие вещи стоит обращать внимание в работе»; "Я поняла, на что нужно обращать особое внимание в воспитании современных детей, я обязательно буду это использовать».

\section{Выводы \\ Conclusions}

Эссе, как форма итогового контроля, может быть логично встроено в структуру учебной дисциплины при условии проблемно выстроенного предметного содержания высокого уровня трудности. В таком случае введение элементов проблемности в итоговое задание воспринимается участниками как естественное продолжение работы над материалами учебной дисциплины. Подготовка итогового эссе предполагает высокую интеллектуальную активность и использование метакогнитивных процессов, в результате чего магистрант соединяет свой профессиональный и личностный опыт с достижениями современной науки.

Проведение экзамена в форме защиты эссе нивелирует многие трудности психологического характера в обучении магистрантов: способствует ощущению большего психологического комфорта, безопасности; поддерживает ощущение компетентности; создает ситуацию успешности; позволяет более разумно распределить временные ресурсы. Это способствует актуализации потребностей (в автономии, компетентности и связанности с другими), которые являются источниками внутренней мотивации как основы субъектности и стремления к саморазвитию.

Таким образом, эссе является психологически и педагогически целесообразной формой итогового контроля, который способствует внедрению результатов обучения в профессиональную деятельность взрослых людей, обучающихся по магистерским программам.

\section{Summary}

Modern sociocultural situation contributes to development of Master's Degree Programs in Russian universities. It requires changes in educational content and techniques. This work presents the experience in approbation of essay as a form of examination (final control) in education of Master's Degree students. Master's Degree Program is named „Preschool education". In the study 20 Master's Degree students were involved - they learned the course "Sociocultural conditions of development of modern pre-school children" as variable part of their curriculum during the first semesters of 2013-2014 and 2014-2015 academic years. Essay as a form of final control (exam) was used. After the exam the incomplete sentences techniqueas a data-gathering tool was applied. Participants were asked to finish sentences about positive and negative aspects of essay as a form of examination. Participants of our research were adults, they were working as kindergarten teachers and studing at Higher 
School of Pedagogy of Immanuil Kant Baltic Federal University as Master's Degree students. Psychological characteristics of adult learning became the main reason for the preference of such form of examination. We tried to use sources of internal motivation as needs for autonomy, competence and relatedness with others, including acknowledgment of important contributions of each participant in the final result. In our study we suppose that using the essay helps to reduce negative effects of exam in traditional forms and activates selfdevelopment of participants. There sults of content-analysis revealed that creation of the essay contributes to generalization, understanding and comprehension of problems in sociocultural conditions pre-schoolers' development. Using of problem elements leads to the situation of intellectual tension which is associated with the presence of obstacles for actions and thoughts. The consequences of intellectual tension are: firstly, efforts to find new ways of action, cognitive activation, reasoned decisions regarding the most important conditions for development of modern preschoolers; secondly, the necessity of independent work with a lot of informational sources, awareness, comprehension and expression of the own point of view; thirdly, creativity and subjectness. Essay as a form of final control (examination) can be logically built into the structure of educational course, but a lecturer should use educational materials of problem type with high level of difficulty. In this case, using of problem elements in the final task are perceived by students as a natural extension of the work with materials of academic course. During creation of the final essay intellectual activity and metacognitive processes are increasing. The examination in the form of essay gives psychological comfort and safety, supportes sense of competence, creates a situation of success for students, helps adults to manage their time and resources more effective. So, it leads to actualization of needs for autonomy, competence, relatedness, which are the sources of internal motivation. Internal motivation is the basis of subjectness and self-development tendency. Thus, the essay is more psychologically comfortable and pedagogically expedient form of final control (examination), especially in adult learning. Furthermore, such work helps Master's Degree students to use learning results in their professional activity.

\section{Библиография References}

Андреев, В.И. (2013). Педагогика высшей школы. Казань.

Гордеева, Т.О., Сычев, О.А., Осин, Е.Н. (2013). Внутренняя и внешняя учебная мотивация студентов: их источники и влияние на психологическое благополучие. Вопросы психологии. 1, 35-45.

Горшкова, В.В. (2014). Онтологизация непрерывного образования. Педагогика. 8, 5356.

Жолковский, А. (2008). Эссе. Иностранная литература. 12, 233-236.

Константинова, Л.В. (2013) Проблема развития магистратуры в условиях реформирования высшего образования. Высшее образование в России. 7, 30-36.

Косырев, В.Н. (2009). Отчуждение учебного труда студента. Высшее образование в России. 11, 138-143.

Люблинский, А. (2007). На перекрестке. Санкт-Петербург.

Макаровская, И.В. (2008). Обучение взрослых: методическое и психологическое обеспечение: учебно-методические материаль. Петрозаводск.

Михайленко, О.И. (2012). Педагогика и психология высшей школь. Нальчик.

Михайлова, О.Б. (2007). Когнитивное развитие и особенности процесса обучения в период ранней и средней взрослости. Психологическая наука и образование. 2, 34 40. 
Несына, C.В. (2014) К вопросу о формах контроля в подготовке магистров. Россия 8 изменяющемся мире. Калининград. 128-132.

Олещенко, Л.М. (2010) Эссе в процессе преподавания социологии. Инновационное образование и экономика. 6, 37-39.

Попков, В.А., Коржуев, А.В. (2010). Теория и практика высшего профессионального образования. Москва.

Щукина, М.А. (2014). Направления исследований саморазвития личности в современной зарубежной психологии. Вопросы психологии. 4, 94-106.

Шохин, А.Н., Кузьминов, Я.И., Ясин, Е.Г. (2005) Методические рекомендации по написанию эссе. Государственный Университет Высшая Школа Экономики Санкт-Петербургский филиал. [reference 11.11.2013]. Retrievedfrom: http://www.hse.spb.ru/edu/recommendations/essay-2005.phtml 